\title{
Sales Force Compensation Mechanisms: A Strategy for Sustainable Competitiveness in the Banking Industry
}

\author{
Amue Gonewa John Ph.D ${ }^{1}$, Igwe Sunny R. Ph.D ${ }^{2}$ \\ Senior Lecturers, Department of Marketing University of Port Harcourt, Nigeria
}

\begin{abstract}
Compensating one's sales force presents challenges, because rewards must be extremely competitive in nature and should provide adequate incentives to motivate employees to do their best. This paper explores ways of developing salesforce compensation mechanisms for sustainable competitiveness in the financial markets. Data were drawn from one hundred and twenty sales managers and three hundred and eighty salesperson making a total of five hundred respondents, selected from money deposit banks in Nigeria. The results of the study shows a strong influence of compensation mechanisms on salesforce performance and also, that amongst the measures of compensation mechanisms, that salary plus commission and bonus, impacts significantly on sales performance. Based on the findings, the study concludes that salesforce compensation mechanisms enhances sales, build salesperson long enduring relationships with employers and provide adequate and sustainable competitiveness. We recommend that money deposit banks in Nigeria financial market should develop good salesforce compensation mechanisms that will enhance sustainable competitive strategy in the market place.
\end{abstract}

\section{Introduction}

The link between Salesforce Compensation and Competitiveness is undoubtedly increasing in research, and debate among scholars and practitioners; especially with the unprecedented roles, benefits and expertise salesforce accrues, and the increasing salesforce switch from firm to firm. Though salesforce provide the firm with gains of selling, closing sales, interactive contact and ambassador of the company, also create avenue for building long term customer relationship, and of recent, a crusader of moving/bringing customers to other firm as the salesforce switch; but their compensation and motivation is treated with high degree of levity. Firms have now seen salesforce compensation as a new strategic window for competitive advantage in the fast response organization (Belmount and Dickson, 2009).

Many salespeople now move horizontally or vertically in the industry for quest of better and higher compensation. Traditionally, compensation methods has been straight salary and, or straight commission which has limited the potential to drive competitiveness. However with the increasing high rate of switch, intense competition, retention challenges and the need to build competitive edge, firms have challenges of devising out new ways and the right mix of compensation methods: salary, commission, drawing account, bonuses, profit sharing, indirect monetary benefits, and expenses of motivating and building salesforce compensation so as to drive competitiveness. Therefore, this paper explores optimal ways of salesforce compensation method in the fast response organization.

\section{Conceptual Foundation}

\section{Prior Research on Salesforce Compensation}

In marketing, research on salesforce compensation has focused primarily on the study of financial compensation plans (e.g. Churchill et al 1979). However, several authors (e.g. Futrell and Vardarajan 1985) have developed models of sales force compensation that incorporate the impact of non-financial compensation mechanisms on sales force performance. Of particular interest to this study are the mix of financial compensation mechanisms and non-financial mechanisms on the performance of sales' persons.

In this study, we focus on the mix of financial compensation and the mix of non-financial compensation mechanisms as a means of enhancing sales force productivity. Research on salesforce compensation plans in Nigeria has indicated that approximately 70 percent has been on the financial aspects of compensation (Maclean, 2008). Again, Chukwu and Morison (2007) posit that 28 percent of research has been in area of non- financial compensation plan. In addition, we focus on the use of the combination of financial and non-financial compensation mechanisms to be consistent with prior research that measures sales force compensation in the banking sector, in which sampling is at the field sales force level.

Virtually, all prior research on sales force compensations rests on the premise that sales people tend to increase and managed their performance by linking it to the compensation they receive from the sales organization. A key element of this research is the notion that sound compensation mechanism will motivate sales people to enhance their performance and achieve higher targets for the organization (Tapan and Sunil, 
2005). The focus of much of the research on sales force compensation is on sales force motivation which will lead to the achievement of greater sales volume. Sales force is not compensated only on the basis of sales volume (Alonzo, 1999; Davidson and Moncrief, 2007; Weitz and Futrell, 2008; Churchill and Walker, 2010). Prior research leaves little doubt that sales force performance is a function of financial compensation and nonfinancial compensations. Thus, commission, profit sharing, bonus, salary and fringe benefits may all be associated with an increased likelihood of motivating a sales person's productivity. The literature is far less clear about which compensation mechanisms are most relevant, how such mechanisms facilitate sales person's productivity. In fact, the literature is not even clear about those compensation plans that prove optimal success on sales people performance.

An important distinction among studies of compensation plans revolves around the level of compensation and the method of payment. People usually are more interested in how much they've earned, rather than how they earned it (William and Rosann, 1999).

Benneth and Chizt (2009) demonstrated that besides setting the pay level, that development of the method by which sales people are pay is very significant. Indeed, these authors found that, the building blocks available to management when constructing a sales compensation plan include salary, commission, drawing accounts, bonus, profit sharing and indirect monetary benefits. These authors speculate that such compensation mechanisms will enhance salespersons productivity. However, these authors did not explain the nature of the influence on sales person's productivity and they call for further research, including work on the combination of the compensation mechanisms or mix to achieve salesforce's performance. There is a need to identify a combination-mix, that determines which of the combination plan that can motivate sales people to perform better.

Martins and Barsalon (2012) posits, that over the past 20 years, there has been significant growth in compensation mechanisms that combine salary with an incentive features. This trend has been at the expense of salary and commission plans. Thus, consistent with the literature on categorization of compensation plan study (Morphy and Srivanav, 2010; Shab and Mick, 2011; Friedman, 2011; Alba and Houston, 2013) demonstrates that combination mix strategy influence sales persons performance and its lead to greater productivity.

An understanding of the combination mix strategy is a fit for both theoretical and practical perspectives. From a theoretical perspective, it is important to note that one single method cannot motivate sales force this day because of high level of competition among the industry players. Passat and Bomskzt (2012) posit that only combination of compensation mechanisms can enhance sales person's performance in our emerging markets. Caleb and Srivanam (2010) find support for combination-mix strategy and concluded by saying that, it is an integrated method of compensation and can solve the problem of changing environment demand.

\section{Salesforce Combination-Mix Strategy}

Salesforce combination - mix strategy, a compensation mechanisms found in the sales management literature, which is receiving increasing attention in marketing studies (Brownson and Huffman 2010; Higgins and Seths 2011; Simonson and Tev 2012; Kayode and Hanson 2009). It is well established that combinationmix strategy is a new methods of compensation (Dahladi and Alihu 2013) and these combinations are use to motivate sales people as against the single method of compensating sales force. Today the sales force is not compensated only on the basis of sales volume. The level of customer satisfaction is an important tool of evaluating and rewarding the sales people. Another emerging trend in combination-mix strategy is the teambased compensation mechanisms. Many business-to-business selling is done through the team selling strategy and cross-functional teams are designed for handling customers objections in a better way (Kelly and Wilson 2008). Many customers are now operating across the territories and geographical boundaries. The performance of the individual sales person is now linked to the performance of the sales people in other territories catering to the same set of customers. So companies are replacing the straight salary based and commission-based compensations with combination-mix strategy which links the pay of the sales people salary plus commission and bonuses. We can therefore hypothesized as follows:

$\mathrm{H}_{1}$ : The higher the salary plus commission and bonus compensation mechanisms, the greater is the influence on sales person's performance.

Prior research on combination plan suggests that allied combination-mix strategy may have an effect on salesperson's performance though the results of Benneth and Folode (2009) implies otherwise. Allied combination methods suggest a relationship between the components of allied methods and sales force performance. A key example of allied method of compensation is the profit sharing plan. This method is prevalent in the Nigeria industries (Kola and Mende, 2010). This method of compensation allows the company to share a part of the profit with its sales staff and sometimes distributes the equity holding of the company in the form of earned shared to increase the stake of the sales people in the organization (Warshaw and Koufaris 
2007). Berna and Disney (2011) posit that the method helps to establish a sense of ownership and cordial relationship with the sales people. The positive effects of allied combination-mix methods on sales people performance are empirically shown in several studies (Kahn and Micah 2006; Bagozzi and Morgan 2007; Davis and Venkat 2009). The argument for the direct effect on sales people is that sales managers has better control over the sales people and it helps to increase the profit and goodwill of the firm.

The second allied method is the special remuneration plan for special sales people. This has a positive effect on sales person performance. Kahn and Ferisk (2012) argued that sales people can be evaluated easily and can be trained for additional responsibilities and managerial positions. They concluded that, there is no enforcement of the additional responsibilities as the salespeople is expected to take up the responsibility on their own. Thirdly, the expense allowance plan is postulated to have a direct and positive effect on salesperson performance. This relationship is in line with the sociological baseline theory called dependency theory, and the argument for the direct effect on sales force performance is that sales people are provided to and fro allowance to meet the expenses of travelling, lodging and boarding. The quota-based compensation plan is a combination model in which the straight salary and commission are linked to the fixed quota given to each salesperson. Upon completion of the quota, the sales person is paid commission at a fixed rate along with his remuneration.

On the basis of these arguments, we suggest the following hypothesis of the influence of allied combination methods on sales people performance.

$\mathrm{H}_{2}$ : $\quad$ Sales person performance is a function of salary, profit sharing plan, special remuneration and expense allowance.

\section{Salary and indirect monetary compensation}

Most salespeople enjoy the same benefit like the production and office workers in a company (Stanton and Spiro, 2005). Sales executives reward their sales people with non financial compensation and indirect monetary benefits. However, as is reflected in sales compensation studies, non financial compensation related to honors, recognition and opportunities for promotion. They help sales people develop a sense of self-worth and belonging to a group (Manson and Katobz, 2010). In accordance with the study of sales compensation, indirect monetary compensation include items that have the same effect as money, though payment is less direct than a salary or commission. These items are referred to as fringe benefits and it includes retirement plans, vocation and insurance. Under these fringe benefits, firms give their sales people paid holidays and provide paid vacations of varying lengths, depending on the employees length of service. As Mabel and Novakt (2008) explained, fringe benefit is characterized by continuous motivation with a focus on attracting desirable sales. Fringe benefits have this relative strong affinity combine with salary to motivate salespeople to perform exceedingly, we propose that there are stronger effects of salary plus indirect monetary benefits on sales people performance.

$\mathrm{H}_{3}$ : $\quad$ Salary plus indirect monetary compensation is a stronger motivation for sales people performance and general business performance.

Firms level characteristics in the form of firm age and firm size are likely to enable the firm to leave up to their responsibilities. In this present day of high competition in the banking industry, firm's longevity is a reality, the number of years a firm has stay in business add to its credibility.

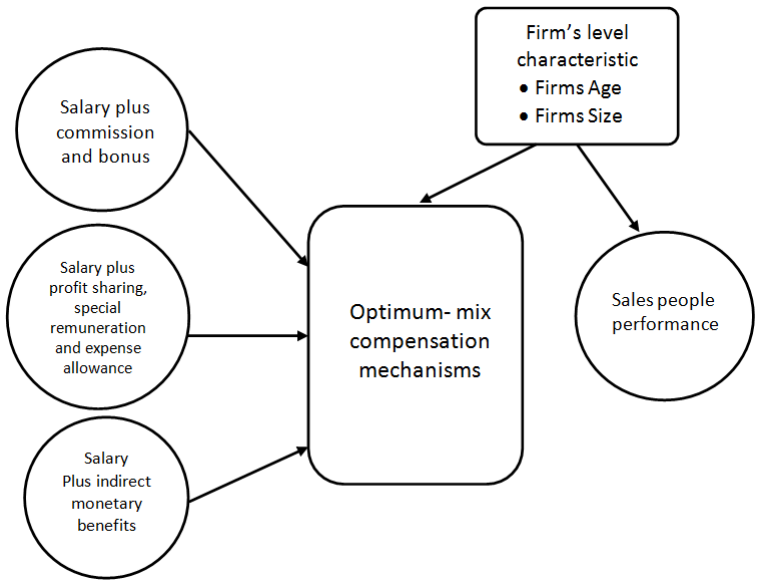

Figure 1: Model of Optimal-mix compensation Mechanisms and Salespeople performance Source: Conceptual from Review of Literature, (2014) 
Firms that are not ethical cannot survive in the market place for so long. Firms that have survived must be more worthy of trust and dependability by virtue of their long survival (Amit and Jean, 2005). Thus, firm age should serve to buttress and validate a firm's optimum-mix compensation mechanisms, making its efforts to put in place this combination plan. The role of age is very evident in the banking industry, it signal credibility market orientation posture and good reputation, it also implies that the firm possesses greater knowledge stocks gained from learning and experience over time. Amit and Jean (2005) posit that the longer a firm has been in business, the more skilled it is in all aspects of strategy and the more effective it is in leveraging optimal-mix compensation strategy.

The experience the firm has over time should provide them with knowledge to put in place a combination plan to generate positive outcome from the salespeople. Thus, we hypothesized as follows:

H4a: The greater the firm's level characteristics, the greater is the influence of salary + commission and bonus compensation mechanisms on salespeople performance and general business performance

4b: The greater the firms' level characteristics, the greater is the influence of salary + profit sharing, special remuneration and expense allowance on performances.

4c: The greater the firms' level characteristics, the greater is the influence of salary + indirect monetary benefits on performance.

We noted previously the relevance of separating the study of performance in sales management in terms of sales people and general business performance. It is of note that sales force performance is an important intermediate goal that merits dependable attention from sales managers. From literature salesperson ability to acquire and retain customers, should be the ultimate goal for salesforce operations (Bussel 2008). Acquisition, which involves notions of loyalty and retention, is a function of both salesforce offerings and operational characteristics, such as interacting and personalization. Sales people can use customers' profile to develop good contact that will lead to better sales responses (Martins, 2008). It follows that salesforce performance, of acquisition, retention will lead to general business performance of increased share profit, sales volume.

Practitioners agree that customer acquisition mechanisms and retention are keys for business profitability (Bossom, 2010). Customer loyalty is crucial for the generation of high business performance, given that, customers lifetime value (CLV) is critical for firm long-term profitability and sales growth (Abams 2011). We propose that salespeople performance will necessitate general business performance. Thus,

Hypothesis 5: The greater the salespersons' performance, the higher is the general performance of the firm.

\section{Context and Sample}

\section{Method}

We selected the money deposit banks in South- South Nigeria as the context for our research work. We did this because money deposit banks represent a successful sector of financial business in Nigeria making it viable for the study of optimal-mix compensation mechanism and salespeople performance. Also, this industry shows a high level o employee moment for better compensation. Again, the money deposit banks provide a universal interface for investors to participate in financial markets, which suggest that the industry is a productive context in which to examine optimal-mix compensation mechanisms. The money deposit bank was also interesting to use because the industry consists of two types of banks. The first, is the old generation banks. The second includes the new generation banks.

Given the nature of the industry, several banks offering financial services have since been out of business and others have merged with others and some acquired. We constructed our sampling frame using multiple sources. We obtained a list of sales people from chamber of commerce, industry and trade directory. We validated the list using yahoo and goggle. The process resulted in a sampling frame of twenty (20) banks.

\section{Data Collection}

We use the interview and questionnaire methods in collecting data for this study. Three hundred and eighty salespeople and one hundred and twenty sales managers making a total of 500 respondents were selected for this study. The data collection yielded 310 responses of the possible 500. Of the 310 responses, 220 were usable for a response rate of 44 percent. In terms of sample composition, $16 \%$ of the responses were the old generation banks, and the remainders were the new generation banks. This composition mirror the industry split and shows that our sample is a true reflection of the banking industry in Nigeria.

\section{Development Of Question Items}

We conceptualized the optimal-mix compensation mechanism as a combination of salary plus commission and bonus (Marvin and Serina, 2009). We assessed the first combination with three items that captured the combination of salary plus commission and bonus. The measurement of allied combination focused 
on salary plus profit sharing, special remuneration and expenses allowances (Young 2007). Accordingly, four items were used to gauged the allied combination as an optimal-mix strategy.

Although indirect monetary compensation has been the focus of considerable research interest (Markins and Jessica 2010), indirect monetary reward that has the same effect as money, though payment is less direct than a salary or commission involves a new perspective and therefore a new measure. Theory suggests that fringe benefits provides an important mechanism for compensating sales force (Stanton and Spiro 1999), thus our operationalization consisted of seven items that assessed the firms indirect monetary compensation mechanisms.

Consistent with our conceptualization, we measured salespeople performance and overall business performance. Managers' perceptions of salesperson effectiveness (relative to their expectations) on items such as number of sales contact, sales closes and the volume of account acquired (Bamoh 2011). We measure overall performance in terms of the profitability, sale volume, sales growth and market share.

For the moderating variables - firms' level characteristics (firm Age and Firm size) were self-reported as the number of years firms has been in business and the number of employees in the firm.

\section{Data Analysis}

Table 1: Result of Confirmatory Factor Analysis Models

\begin{tabular}{|c|c|c|c|c|c|c|c|c|}
\hline Measurement models & $\begin{array}{l}\text { Factor } \\
\text { loading }\end{array}$ & $\begin{array}{l}\text { Construct } \\
\text { reliability }\end{array}$ & $\begin{array}{l}\text { Average variance } \\
\text { extracted }\end{array}$ & NNFI & CFI & SRMR & GFI & $\mathrm{X}^{2}$ (df.value) \\
\hline Firm's level characteristic & $.52-.70$ & .73 & .60 & .80 & .82 & .09 & .82 & $102.3(25, \mathrm{P}<.01)$ \\
\hline $\begin{array}{l}\text { Salary + Commission and } \\
\text { Bonus }\end{array}$ & $.69-.82$ & .84 & .74 & .82 & .90 & .06 & .81 & $120.5(42, \mathrm{P}<.01)$ \\
\hline $\begin{array}{l}\text { Salary + profit sharing, } \\
\text { special remuneration ad } \\
\text { allowance }\end{array}$ & $.73-.90$ & .90 & .77 & .91 & .95 & .07 & .83 & $75.6(36, \mathrm{P}<.01)$ \\
\hline $\begin{array}{l}\text { Salary + indirect monetary } \\
\text { benefits }\end{array}$ & $.59-.94$ & .92 & .81 & .93 & .90 & .08 & .84 & $130.5(43, \mathrm{P}<.01)$ \\
\hline Sales people performance & $.64-.91$ & .95 & .83 & & & & & \\
\hline $\begin{array}{l}\text { General Business } \\
\text { Performance }\end{array}$ & $.76-.93$ & .94 & .72 & .91 & .95 & .07 & .86 & $95.5(43, \mathrm{P}<.01)$ \\
\hline
\end{tabular}

NOTE NNFI = Non normal Fit Index; CFI = Comparative Fit Index; SRMR = Standardized root mean square residual, GFI $=$ Goodness of Fit Index; $\mathrm{df}=$ degree of freedom.

Table 2: Descriptive Statistics

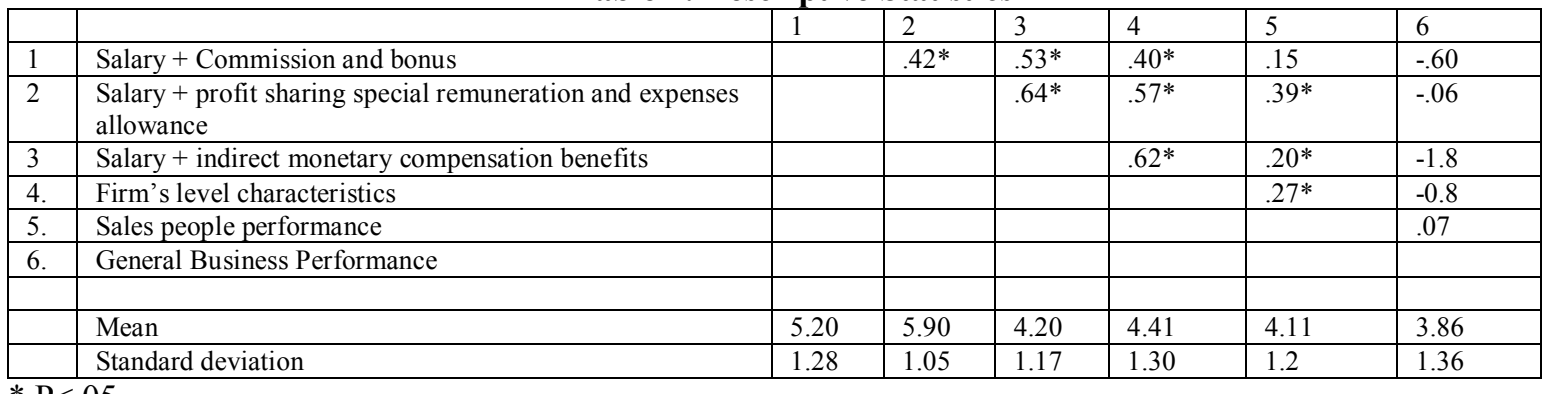

We conducted confirmatory factor analysis (CFA) to assess the validity of our measurement models. We grouped similar constructs into a measurement models, as it is shown in table 1 . The confirmatory factor analysis models show adequate levels of fit, and all the factor loadings were greater than .4. All the composite reliability were greater than.

.70 (Nunnally and Bernstein 1994). The average variance extracted were greater than .50. All observed variables had significant factor loadings linked with the latent constructs, which provided evidence of convergent validity (Anderson and Gerbin 1988).

We assessed discriminant validity with confirmatory factor analyses models of paired constructs (Bagozzi, Yi and Philips, 1991). In all cases, we obtained a significantly lower chi-square value for the unconstrained

Table 3: Least Squares Results

\begin{tabular}{|c|c|c|c|c|c|}
\hline \multirow[t]{2}{*}{ Variable category } & \multirow[t]{3}{*}{ Independent variable } & \multicolumn{4}{|c|}{ Dependent Variable } \\
\hline & & \multicolumn{2}{|c|}{$\begin{array}{l}\text { Salespeople } \\
\text { Performance }\end{array}$} & \multicolumn{2}{|c|}{$\begin{array}{l}\text { General } \\
\text { Business }\end{array}$} \\
\hline Moderator & & $\mathrm{B}$ & SE & $\mathrm{B}$ & SE \\
\hline & Firm Age (FA) & -.1 .72 & .112 & -.020 & .106 \\
\hline Mechanisms & Salary + commission and Bonus (SCB) & $.28 *$ & .072 & -.067 & .084 \\
\hline
\end{tabular}




\begin{tabular}{|c|c|c|c|c|c|}
\hline & $\begin{array}{l}\text { Salary }+ \text { profit sharing remuneration and allowance } \\
\text { (SPRA) }\end{array}$ & .202 & .609 & $-1.05^{*}$ & .564 \\
\hline & Salary + indirect monetary benefits (SIMB) & .045 & .075 & -.054 & .070 \\
\hline Interactions & SCB x FA & -.060 & .062 & $.180 *$ & .060 \\
\hline & SPRA x FA & $.108 *$ & .042 & .014 & .040 \\
\hline & SIMB x FA & $.071 *$ & .038 & $-.061 *$ & .036 \\
\hline Performance & Sales people performance & - & & $.584 *$ & .086 \\
\hline Overall model fit & Model R $^{2}$ & .32 & & .51 & \\
\hline
\end{tabular}

a. We report standard errors and one-tailed tests for hypothesized effects.

Model $(\mathrm{P}<.01)$, demonstrating discriminant validity.

Our procedures of in-depth interviews, along with a visual inspection of the items, provide evidence of validity. Again, Table 2 shows the correlations and descriptive statistics of composite scales for hypotheses testing.

\section{Results}

In terms of the two related dependent variables (sales people performance and general business performance), we estimated a three-stage least squares model as in Table 3. We created indicators for all latent constructs by averaging the item scores for the respective measures. For the interaction hypotheses, we created product terms for the concerned explanatory variables.

We specified the statistical model as follows:

$$
\begin{aligned}
\mathrm{SP}_{\mathrm{i}}= & \alpha_{0}+\alpha_{1} \mathrm{FA},+\alpha_{2} \mathrm{SCB},+\alpha_{3}(\mathrm{SCB}, \mathrm{x} \text { FA; }) \\
& +\alpha_{4} \mathrm{SPRA} ;+\alpha_{5}(\mathrm{SPRA} ; \mathrm{x} \text { FA; })+\alpha_{6} \mathrm{SIMB} ; \\
& +\alpha_{7}(\mathrm{SIMB} ; \mathrm{xFA})+\varepsilon_{1} \\
& \\
\mathrm{BP}_{\mathrm{i}}= & \beta_{0+} \beta_{\mathrm{i}} \mathrm{FA} ;+\beta_{2} \mathrm{SCB} ;+\alpha_{3}\left(\mathrm{SCB}_{\mathrm{i}} \times \mathrm{FA}:\right)+ \\
& \alpha_{4} \mathrm{SPRA}_{\mathrm{i}}+\alpha_{5}\left(\mathrm{SPRA}_{\mathrm{i}} \mathrm{FA}_{\mathrm{i}}\right)+\alpha_{6} \mathrm{SIMB}_{\mathrm{i}} \\
& +\alpha_{7}\left(\mathrm{SIMB}_{\mathrm{i}} \times \mathrm{FA}_{\mathrm{i}}\right)+\varepsilon_{2}
\end{aligned}
$$

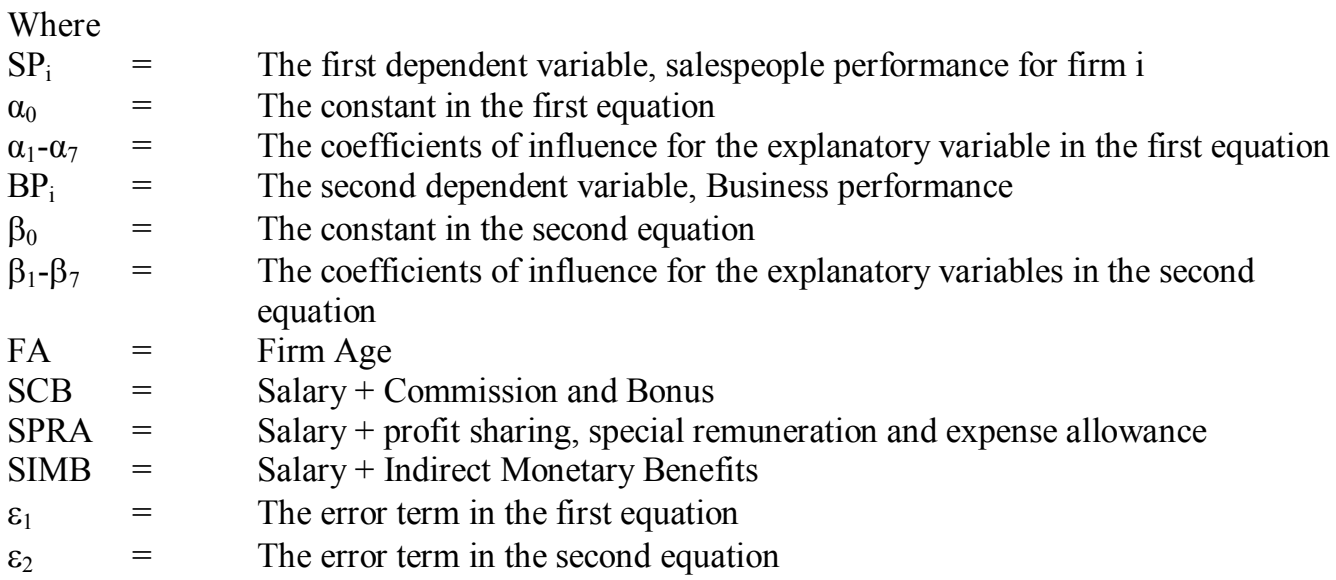

We hypothesized that salary plus commission and Bonus influence sales people and Business Performance Variables. Consistent with the hypothesis, our results show that salary plus commission and Bonus influence performance such that salary plus commission and bonus increases the performance of sales people and the entire business (Hypothesis $1 ; \mathrm{b}=.28, \mathrm{P}<.05$ ).

We find partial support for the interaction between optimal-mix compensation and firm age such that salary plus commission and bonus influence performance (Hypothesis $4: b=-.060, \mathrm{P}<.05$ ). This interaction is not significant for business performance. For the interaction between salary plus profit sharing, special remuneration and expense allowance and firm age, we find support for sales people performance such that allied compensation enhance the salespeople performance (Hypothesis $2: \mathrm{b}=.108, \mathrm{P}<.05$ ), this interaction is not significant for general business performance.

However, for salary plus indirect monetary compensation benefits, the results are opposite to that hypothesized, suggesting that salary plus fringe benefits decrease the business performance (Hypothesis 3: $6=-$ $.054, \mathrm{P}<.05)$. 
We hypothesized that firm-level characteristics (i.e. firm age) moderate the impact of optimal-mix compensation mechanism on the performance variables. Our result shows no significant moderating effects for age and SCB (Hypothesis 4a) but shows a significant moderating effect for SPRA and SIMB. (Hypothesis 4b and $4 \mathrm{c})$.

On the hypothesis concerning the positive influence of salespeople performance on business performance, our hypothesis is supported. Higher levels of salespeople performance lead to better business performance (Hypothesis 5: $\mathrm{b}=.584, \mathrm{P}<.05$ ).

In the overall model fit, 32 percent of the variability in our salespeople performance variable (dependent variable), was accounted for by the optimal-mix compensation mechanisms (the independent variables) i.e. $\left(\mathrm{r}^{2}-=.32\right)$, and 51 percent of the variability in our second dependent variable, business performance, was explained by our independent variables $\left(r^{2}=.51\right)$. We can as well gauge the relative effects of a particular independent variable using standardized regression coefficients; for all the predictor variables. The standardized regression coefficients for statistically significant effects ranges from -2.56 to 1.86 for salesforce performance and from -1.86 to 6.64 for general business performance. The regression coefficients and standard errors are reported in table 3.

\section{Discussion}

In this research work, we attempted to offer some understanding of salespeople performance through optimal-mix compensation perspectives. We advanced the notion of optimal-mix compensation mechanisms, identified a set of combination that are relevant to salespeople context and tested their impact on performance outcomes. We conceived firms level characteristics as providing a platform for leveraging optimal-mix strategies. Thus, we took a disaggregated position on performance (salespeople performance and business performance), as we posit that sales managers should focus on both sales-based and business-related metrics to assess their firm's performance. Our results indicate notable findings with respect to using optimal-mix compensation strategies.

Our results show that salary plus commission and Bonus is critical for superior salesforce performance in the banking sector. In this dynamic market environment, there is a payoff in compensating salespeople with optimal-mix combination strategies (salary + commission and Bonus). Combination plan in the form of salary plus commission and bonus allows certain degree of control and provide an incentive as well as offer a bonus for the accomplishment of a specific good. Here, salary plus commission and bonus provides the requisite synergy to enhance salespeople performance. This combination-mix strategies are likely to be firm specific, thereby contributing to the firm's competitive advantage.

We argued that salary plus profit sharing, special remuneration and expenses allowance as a combination-mix compensation mechanism provides the salespeople with the ability to take advantage of challenging tasks. Our results show that as we hypothesized, the interplay between salary plus profit sharing, special remuneration and expense allowance plan is quite complex. First, from the standpoint of sales people performance, profit sharing increases the stake of the salespeople in the firm and helps to establish a sense of ownership and cordial relationship which enhance salesforce performance. Second, the interaction between salary plus profit sharing, special remuneration, and expense allowance does not affect business performance, contrary to our hypothesis. This is because several amount spent in the form of salary, profit sharing, special remuneration and expenses allowance to motivate salespeople actually affects overall firm performance.

However, the positive effect of salary plus profit sharing, special remuneration and expense allowance on salespeople performance juxtaposed with the negative effect of salary plus profit sharing, special remuneration and expense allowance on general business performance limits the possibility of different antecedents for the two performance measures. From the above explanation, we agree that the interplay is complex, and so more research is needed to understand the interplay between salary together with profit sharing, special remuneration and expense allowance on salespeople performance and general business performance.

We do not find statistical support for salary plus indirect monetary compensation plans, the results indicate marginal evidence $(\mathrm{P}<.05)$ that the more salary and indirect monetary compensation paid to salespeople, the more their performance and the general business performance. This reiterates the popular saying that salary plus fringe benefit motivates salespeople. They may serve as a motivator to salespeople performance but their effects may influence general business performance.

While we do not find statistical support for the interaction between firm-level characteristics and salary plus commission and Bonus on performance, our result show a very insignificant relationships but the interaction between salary plus profit sharing, special remuneration and expense allowance and firm-level characteristics shows a positive effect on performance.

Finally, our study documents the influence of salespeople performance on the general business performance. In reality, the outcome of the salespeople effectiveness that necessitate the general performance of the organization. It is the salesforce that contact, attract, convert and retain customers to tap their lifetime values 
that influence general business performance. The power of salespeople to covert customer into actual purchase is critical and doing so within a framework that delivers profits and enhances firm's performance.

\section{Implications}

Our study makes the following contributions to the growing literature on optimal-mix compensation strategies: we identify, conceptualize and measure three optimal-mix combinations with salary and use firmlevel data to contribute new empirical insights on salesforce compensation in the banking industry. (2) Our framework explicitly links optimal-mix combination strategies to organization performance thus bringing forth the theoretical insights of the optimal-mix compensation views of the firm. (3) Finally, we extend the literature on salespeople compensation by developing and testing a valid and reliable measure of profit sharing, special remuneration and fringe benefits.

Our research provides several insights for sales managers who want to implement sales-related strategies to focus on optimal-mix compensation strategies for effective salespeople performance. We recommend that sales managers use optimal-mix combination strategy to motivate their sales teams. Again, our results re-iterate the popular view that creating and maintaining an effective salespeople is critical to superior sales performance in the banking industry. Hence salespeople compensation deserves priority status for optimal results. We advance a framework for sales managers to understand the optimal-mix combination in terms of salary plus other combination plans.

\section{Area Of Future Study}

The context for our study is the banking industry. The industry provided a worthwhile setting because the optimal-mix combination plans involved are particularly relevant. However, the setting is relatively unique and to ensure generalization, the effects of optimal-mix combination should be examined in other contexts. Such as the telecommunication industry, the pharmaceutical industry and the hospitality industry to see whether is true everywhere. They are emphasized on quantitative effect of optima-mix compensation strategies on performance outcomes, the qualitative effect of the use of optimal-mix combination plans is not examined, and future work should look at the influence of qualitative effect of optimal-mix on performance. Again, our model we put up in this study considers firms-level characteristics in terms of firm age, other firms-level characteristics are not considered. Future research should consider other firms' level characteristics. Again, the positive effect of salary plus profit sharing, special remuneration and expense allowance on salespeople performance juxtaposed with the negative effect of salary plus profit sharing, special remuneration and expenses on general film performances limits. The possibility of different antecedents for the two performance measures is complex. Therefore more research is needed to understand the interplay between salary together with profit sharing, special remuneration and expense allowance on salespeople performance and firm performance.

\section{References}

[1]. Alonzo, Vincent (1999), 'Money is not Everything', Sales and Marketing Management, 6(4), 28 -30.

[2]. Abams, K. T. (2011) 'Sales Force Compensation: An Empirical Investigation of factors related to use of salary versus incentive compensation, Journal of International Research in Marketing, 26 (1) 1-14.

[3]. Alba, S.B. and Houton, A. O. (2013) 'Customer Satisfaction. Based Incentive Systems: Salesperson Considerations' International Journal of Personal Selling, 18(3) 32-46.

[4]. Amit, S and Jean, L.J. (2005) 'Organizational Capabilities in E-Commerce: An Empirical Investigation of E-Brokerage Service Providers, Journal of the Academy of Marketing Science, 33 (3), 360-375.

[5]. Anderson, C. B. and Gerb, T. K (1988) 'Compensation Strategy for Salesforce Success' Journal of Sales Management, 16 (4) 88102 .

[6]. Bagozzi, C. T. and Morgan, A.D. (2007) 'Salespeople Compensation Mechanisms: An Empirical Investigation, Journal of Sales Management Research, 26(1), 42-53.

[7]. Bamog, K. K. (2011) 'Mix-combination Compensation Plan: Impact on Sales Performance, International Journal of Sales Management Research and Strategy, 21(5), 44-60.

[8]. Benneth, Y. C. and Chizt, O. B (2009) Salary Plus Commission Compensation Plan, Journal of Sales Management Research, 12(2) 112-124.

[9]. Berna, S. a. and Disney, D. K (2011) 'The Moderating Effect of Firm-Level Characteristics on Compensation Strategies and Salesforce Performance, Journal of Business and Marketing Studies, 6 (2) 88-102.

[10]. Bossom, Y.M (2010) 'Fringe Benefits as a Compensation Strategy for Optimality, Journal of Sales Management Research and Strategy, 20 (1) 1-15.

[11]. Brownson, D. S. and Huftman, A.C. (2010) Compensation Strategy for Sales Performance, International Journal of Personal Selling, 12 (3): 240-256.

[12]. Caleb, H.G. and Srivanam, M. N (2010) The Effects of Sequential Introduction of Mix-Compensation Plans: Journal of Research in Sales Management Strategy, 5 (4): $71-88$

[13]. Churchill, G. A; Ford, N.M and Walker, O. C. (1979), Personal Characteristics of Sales Persons and Attractiveness of Alternative Rewards. Journal of Business, 6(1): 24-51.

[14]. Danladi, C.O and Alihu, G.G. (2013) 'How Does Mix Compensation Plans Affect Salesforce Performance: Journal of Applied Sociology, 20(1):46-55.

[15]. Davidson, D.B and Moncrief, C. F. (2007) The Impact of Salary on Mix-Combination Plan Structure; International Journal of Sales Management Research and Strategy, 17(2): 102-118. 
[16]. Davis, K. S. and Venkat, T.B (2009) 'Salesforce Goal Structure and Goal Determination Processes; An Integrative Framework; Contemporary Journal of Sales Management, 7(4): 128-140.

[17]. Futrell, C. M. and Vardarajan, P.R. (1985) Marketing Executives 'Perspectives of Equitable Salary Increa ses; Industrial Marketing Management, 14(2): 59-67.

[18]. Friedman, K.C (2011), Problems and Prospects of Mix-Combination Strategy in the Banking Industry; Journal of Business and Marketing Studies, 6(2):102-118.

[19]. Higgins, E. F. and Seths, C. O (2011) 'The Commitment Trust Theory of Relationship Marketing; Journal of Service Marketing, $20(1), 56-67$.

[20]. Kayode, B.A. and Hanson, H.S. (2009), Compensation Structure and Attitude Affect; Journal of Social Psychology, 32(1)206-220.

[21]. Kahn, B.S. and Micah, Y.T. (2006) 'Workman Compensation and Motivational Expectations, Social Research Journal; 6(3):24-40.

[22]. Kahn, B.S. and Ferisk, L.K (2012) Salespeople motivational Strategies: Contemporary Perspectives; Journal of Research in Sales Management and Strategy, 22(2) 102-116.

[23]. Kelly, W. Z and Wilson, B.A. (2008) Salesforce Entertainment Activities, 'Industrial Marketing Management, 11(2):227-235.

[24]. Kola, A.A. and Mende, D. E. (2010) 'Adjustable Compensation Plan: Strategy for Profitable Relationship; International Journal of Research in Sales Management and Strategy, 20(5) 112-230.

[25]. Mabel, S.S. and Novakit, T. Y. (2008) 'A Contribution to the Theory of Compensation, Journal of Sales Management Research, 20(2), 49-60.

[26]. Maclean, C.T. (2008) 'Commission and Salary Plus Allied compensation Plan, Journal of Social Research in sales Management, 12(4):121-138.

[27]. Manson, T.K. and Katobz, Y.P (2010) 'Compensation Issues: Salesforce Perspectives; International Journal of Sales Management and Strategy: 20 (1): 25-49.

[28]. Martins, S.S. and Barsalon, B.G. (2012) 'The Best Practice in Rewarding Salespeople, Journal of Social Research 5(1) 40-53.

[29]. Martins, K.T. (2008) Salesforce Motivational Strategies in Fast Response Organization. Journal of consumer Research, 21(5): 98102 .

[30]. Marvin, N. K. and Serina, B.F. (2009) Salesforce Compensation Alternatives: Effect on Performance, Journal of Marketing Studies, 7(2):125-147.

[31]. Markins, B.F. and Jessica, M.N (2010) Simulational Strategy for Salesperson Performance, International Journal of Sales Management and Strategy, 20(1) 50-61.

[32]. Morison, C.Y (2007) 'Salesforce Combination Mix-Strategy: The Performance Perspectives. Journal of Social Research in Sales Management, 11(2) 56-72.

[33]. Morphy, K.O. and Srivanav, R. B. (2010) 'Salary and Indirect Monetary Compensation in the Service Firms, Journal of Service Marketing, 19(3), 102-124.

[34]. Nunnally, U. L. and Bernstein, C. P. (1994) 'Sales Management' 3 rd ed. McGraw Hill U.S.A.

[35]. Passat, K. T. and Bomstzt, C.E. (2012) 'Salesforce Compensation and Salesperson Performance. Journal of Sales Management and Strategy.

[36]. Shab, M. K. and Mick, B.T. (2011) Salary Plus Commission Incentives Reward and Performance of Telecommunication Industry: International Journal of Personal Selling 16(1) 1-15.

[37]. Simonson, I. F. and Tev, B.B (2012) Allied Strategy and Sales Performance, Journal of Sales Management and Strategy, 22(5) 161178.

[38]. Stanton, W.J. and Spiro, R (2005), Management of a Sales Force, $10^{\text {th }}$ edition, Irwin, McGraw Hill.

[39]. Tupan, K. P and sunil, S (2005) Sales and Distribution Management, first edition, Oxford University Press-India. 